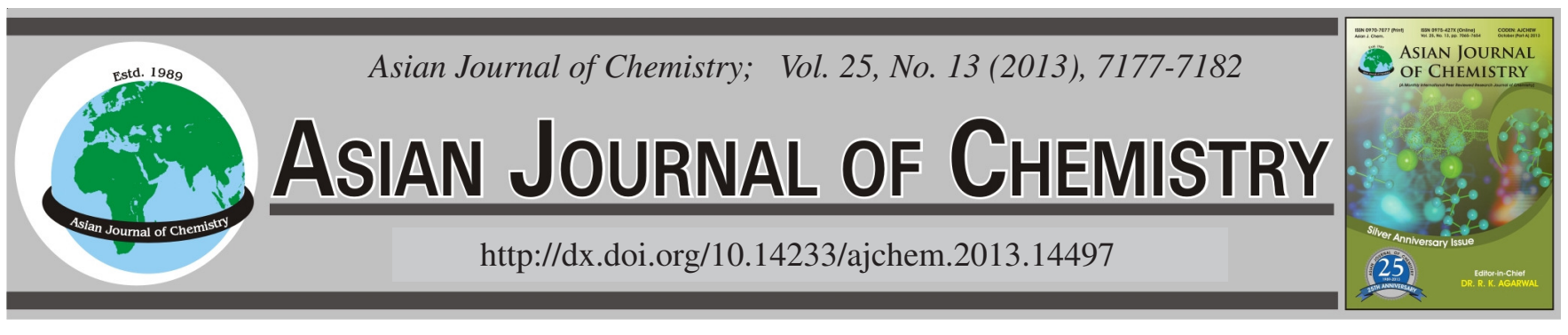

\title{
Development and Validation of an Isocratic, Sensitive and Facile RP-HPLC Method for Rapid Analysis of 5-Fluorouracil and Stability Studies Under Various Stress Conditions
}

\author{
Nazrul HaQ ${ }^{1,2}$, Faiyaz Shakeel ${ }^{1,2,}$, Fars K. Alanazi ${ }^{1,3}$, Awwad A. Radwan ${ }^{3}$, Mohammad Ali ${ }^{2}$ and Ibrahim A. Alsarka ${ }^{1,2}$
}

${ }^{1}$ Center of Excellence in Biotechnology Research, King Saud University, Riyadh-11451, Saudi Arabia

${ }^{2}$ Department of Pharmaceutics, College of Pharmacy, King Saud University, P.O. Box 2457, Riyadh-11451, Saudi Arabia

${ }^{3}$ Kayyali Chair for Pharmaceutical Industry, Department of Pharmaceutics, College of Pharmacy, King Saud University, P.O. Box 2457, Riyadh-11451, Saudi Arabia

*Corresponding author: Tel: +966 537507318; E-mail: faiyazs@ fastmail.fm

\begin{abstract}
The objective of the present investigation was to develop and validate a RP-HPLC method for rapid analysis of a cytotoxic drug 5fluorouracil in bulk drug, marketed injection, water-in-oil (w/o) nanoemulsion and double water-in-oil-in-water (w/o/w) nanoemulsion. The chromatographic identification was achieved on Lichrosphere $250 \mathrm{~mm} \times 4.0 \mathrm{~mm} \mathrm{RP} \mathrm{C} \mathrm{C}_{8}$ column having a $5 \mu \mathrm{m}$ packing as a stationary phase using methanol:water $(50: 50 \% \mathrm{v} / \mathrm{v})$ as a mobile phase, at a flow rate of $1 \mathrm{~mL} / \mathrm{min}$ with UV detection at $254 \mathrm{~nm}$. The proposed method was validated for linearity, accuracy, precision, robustness, sensitivity and specificity. The utility of the method was verified by assay of drug in various pharmaceutical formulations. The proposed method was found to be precise, accurate, robust, sensitive and specific. The amount of 5-fluorouracil in marketed injection, developed water-in-oil nanoemulsion and double water-in-oil-in-water was found to be more than $99 \%$. The proposed method successfully resolved drug peak in the presence of its degradation products which established stability-indicating property of the proposed method. Overall, these results indicated that the proposed method can be successfully employed for routine analysis of 5-fluorouracil in bulk drug and various pharmaceutical dosage forms.
\end{abstract}

Key Words: RP-HPLC, 5-Fluorouracil, UV detection, Nanoemulsion, Double nanoemulsion.

\section{INTRODUCTION}

The 5-fluorouracil (5-FU), a pyrimidine analogue which is extensively used as an antineoplastic agent in most of the malignancies such as breast, lung and gastrointestinal tract cancers $^{1,2}$. Due to incomplete and erratic bioavailability upon oral administration, intravenous injection and topical cream of 5-fluorouracil are currently available in the market for clinical use ${ }^{3}$. Because of its structural resemblance to natural pyrimidines, it interferes with nucleic acid synthesis, inhibits DNA synthesis and eventually halts cell growth ${ }^{4}$.

Literature survey revealed that many analytical methods have been reported for the determination of 5-fluorouracil in bulk drugs, pharmaceutical dosage forms and biological fluids. Most of these methods are reported for analysis of 5-fluorouracil in blood plasma and their application to pharmacokinetic studies. Several high performance liquid chromatography (HPLC) methods have also been reported for analysis of 5fluorouracil in biological fluids like plasma ${ }^{1,25-22}$. Most of these HPLC methods used mass spectrophotometer as the detector which is too expensive for analysis. HPLC method with solid phase extraction has been reported for analysis of 5-fluorouracil in aqueous solutions and environmental samples ${ }^{23}$. Gas chromatographic methods were also employed for its analysis in human plasma ${ }^{3,5,10,24-28}$. 5-Fluorouracil in biological fluids was also quantified by spectrophotometric method ${ }^{29}$ and by capillary electrophoresis ${ }^{30}$. But still few analytical methods have been reported for its analysis in bulk drug and pharmaceutical dosage forms. Only one stability-indicating HPLC method has been reported for simultaneous analysis of cisplatin and 5-fluorouracil in pharmaceutical injection ${ }^{31}$. Only three HPLC methods have been reported for analysis of 5-fluorouracil in bulk drug and other in-house developed pharmaceutical formulations ${ }^{18,32,33}$. One rapid and precise colorimetric method is also reported for analysis of 5-fluorouracil in bulk drug and pharmaceutical dosage forms with linearity range of 0.4-11 $\mu \mathrm{g} / \mathrm{mL}^{34}$. This method is not stability-indicating one and hence could not be used for stability studies. The parent drug stability test guidelines of international conference on harmonization (ICH) suggested that stress studies should be carried out on drug products to establish its inherent stability characteristics, leading to identification of its degradation products and hence 
supporting the suitability of the proposed assay methods ${ }^{35}$. It also requires that analytical assay methods for stability samples must be stability-indicating in order to determine shelf life of drug products.

With this background, the aim of present study was to develop and validate a cost effective, rapid, facile, precise, accurate, robust and stability-indicating reverse phase HPLC method coupled with UV detection for rapid analysis of 5fluorouracil utilizing isocratic elution, taking into considerations a variety of ICH-recommended test conditions. The novelty of this method is that it used very cheaper mobile phase (methanol and water) with $\mathrm{C}_{8}$ RP-HPLC column for rapid analysis of 5-fluorouracil as compared to previously reported methods (Table-1). Moreover, we have first time analyzed 5fluorouracil in developed double w/o/w nanoemulsion. The developed method would be utilized for studying the stability of 5-fluorouracil in pharmaceutical formulations and marketed injection.

\section{EXPERIMENTAL}

5-Fluorouracil was obtained as gift sample from Alfa Aesar, A Johnson Metthey Company (Ward Hill, MA). HPLC grade methanol, hydrochloric acid, sodium hydroxide and hydrogen peroxide were purchased from BDH Laboratory supplies (Liverpool, UK). Ultra-pure water was obtained from ELGA (Wycombe, Bucks, UK) water purification unit. Lauroglycol-90 and Transcutol-HP were kind gift samples from Gattefosse (France). Isopropyl alcohol (IPA) and Cremophor-EL were purchased from BDH Laboratory supplies, UK and BASF, UK, respectively. All other chemicals and reagents used were of analytical reagent (AR) grade. 5Fluorouracil w/o nanoemulsion was developed using Lauroglycol90 as the oil phase, IPA, Transcutol-HP and deionized water as surfactant, cosurfactant and aqueous phase, respectively and evaluated in our laboratory. Double w/o/w nanoemulsion of 5-fluorouracil was developed using w/o nanoemulsion as the oil phase, Cremophor-EL, Transcutol-HP and deionized water as surfactant, cosurfactant and aqueous phase, respectively.

Chromatographic identification was performed at room temperature $\left(25 \pm 1^{\circ} \mathrm{C}\right)$, with Waters HPLC system (Waters, USA) equipped with a 600 LC pump, 717 autosampler, quaternary LC-10A VP pumps, a programmable UV-visible variable-wavelength detector, SPD-10AVP column oven, a SCL 10AVP system controller (Shimadzu, Japan) and a inline vacuum degasser was used. The software used in the system was Millennium, version 32. The chromatographic performance was achieved on a Lichrosphere $250 \mathrm{~mm} \times 4.6 \mathrm{~mm} \mathrm{RP}$ $\mathrm{C}_{8}$ column (Phenomenex, USA) having a $5 \mu \mathrm{m}$ packing as a stationary phase. The mobile phase consisted of methanol: water $(50: 50 \% \mathrm{v} / \mathrm{v})$. The elution was performed at a flow rate of $1.0 \mathrm{~mL} / \mathrm{min}$ with UV detection at $254 \mathrm{~nm}$. Samples $(10 \mu \mathrm{L})$ were injected using a Waters auto sampler.

Preparation of drug stock solution for calibration curve: Calibration curve for 5-fluorouracil was prepared in the range of $0.1-20 \mu \mathrm{g} / \mathrm{mL}$. Stock solution of $100 \mu \mathrm{g} / \mathrm{mL}$ concentration was prepared. Serial dilutions from this stock solution were made by diluting the required aliquots with mobile phase to get concentration in the range of $0.1-20 \mu \mathrm{g} / \mathrm{mL}$.

Method development: Various solvent systems as mobile phase were tried for the development of suitable RP-HPLC method for the analysis of 5-fluorouracil in the pharmaceutical formulations. The selection of the solvent system was decided on the basis of the sensitivity of the assay, suitability for stability studies, time required for the analysis, peak parameter, ease of preparation and cost effectiveness of solvents. Based on above criterion, we had tried methanol-water, methanolphosphate buffer, acetonitrile-phosphate buffer, methanolsodium percholate buffer and acetonitrile-sodium percholate buffer as mobile phases at different proportions. Out of tried mobile phases for chromatographic analysis, a combination of methanol-water (50:50\% v/v) was selected as final eluent for further studies.

Validation studies: The proposed RP-HPLC method was validated according to $\mathrm{ICH}$ guidelines for the linearity, accuracy, precision, sensitivity, robustness and specificity.

Freshly prepared linearity solutions of different concentration $(0.1-20 \mu \mathrm{g} / \mathrm{mL})$ were used for construction of calibration curves. The mobile phase consisting of methanol-water (50:50 $\% \mathrm{v} / \mathrm{v}$ ) was delivered at $1 \mathrm{~mL} / \mathrm{min}$ for column equilibration; the baseline was monitored continuously during this process. The detection was performed at $254 \mathrm{~nm}$. The prepared dilutions were injected in triplicates and peak areas were recorded for each dilution and concentration was plotted against peak area.

Accuracy of the proposed method was determined by the standard addition method. The standard 5-fluorouracil solution $(8 \mu \mathrm{g} / \mathrm{mL})$ was spiked with $0,50,100$ and $150 \%$ extra 5-fluorouracil standard solution and were reanalyzed by the proposed method. Experiments were performed in triplicates. Recovery (\%), RSD (\%) and standard error for each concentration were calculated.

TABLE-1

COMPARISON OF CURRENT HPLC METHOD WITH VARIOUS ANALYTICAL METHODS REPORTED FOR ANALYSIS OF 5-FLUOROURACIL IN BULK DRUG/ DOSAGE FORMS

\begin{tabular}{|c|c|c|c|c|c|c|}
\hline Sample matrices & Mobile phase & Method & Detection mode & $\begin{array}{c}\text { Linearity range } \\
(\mu \mathrm{g} / \mathrm{mL})\end{array}$ & $\begin{array}{c}\text { Stability-indicating } \\
\text { property }\end{array}$ & Reference \\
\hline Injection & $\begin{array}{c}0.05 \mathrm{M} \text { potassium } \\
\text { dihydrogen phosphate }\end{array}$ & HPLC & $\mathrm{UV}$ at $260 \mathrm{~nm}$ & $2-40$ & No & 18 \\
\hline Bulk drug & $40 \mathrm{mM}$ Phosphate buffer & HPLC & $\mathrm{UV}$ at $260 \mathrm{~nm}$ & $0.1-2$ & Yes & 32 \\
\hline Bulk drug/tablets & $\begin{array}{l}50 \mathrm{mM} \text { potassium } \\
\text { dihydrogen phosphate }\end{array}$ & HPLC & $\mathrm{UV}$ at $254 \mathrm{~nm}$ & $10-100$ & Yes & 33 \\
\hline Bulk drug & - & Colorimetric & $\begin{array}{l}\text { Colorimetric at } \\
350 \mathrm{~nm}\end{array}$ & $0.4-11$ & No & 34 \\
\hline $\begin{array}{l}\text { Bulk drug/injection/ } \\
\text { nanoemulsions }\end{array}$ & Methanol: water (50:50) & HPLC & $\mathrm{UV}$ at $254 \mathrm{~nm}$ & $0.1-20$ & Yes & $\begin{array}{l}\text { Present } \\
\text { method }\end{array}$ \\
\hline
\end{tabular}


Precision of the proposed method was determined as repeatability (intraday precision) and intermediate precision. Repeatability studies were performed by analysis of four different concentrations of the drug $(8,12,16$ and $20 \mu \mathrm{g} / \mathrm{mL})$ in triplicate on the same day. Intermediate precision of the method was checked by repeating the studies on three different days. Detection (LOD) and quantification (LOQ) limits of the proposed experiment were determined by the standard deviation method. For determination of LOD and LOQ, blank samples (samples without 5-fluorouracil) were injected in triplicate and the peak area of these blank samples was recorded. LOD and LOQ were determined from the slope $(\mathrm{S})$ of the calibration curve and the standard deviation of the response for the blank sample, standard deviation by use of the formulae $\mathrm{LOD}=3.3$ $\times \mathrm{SD} / \mathrm{S}$ and $\mathrm{LOQ}=10 \times \mathrm{SD} / \mathrm{S}$.

The robustness of the proposed method was determined to evaluate the effect of deliberate variation of chromatographic conditions on determination of 5-fluorouracil. The target concentration $(8 \mu \mathrm{g} / \mathrm{mL})$ was selected for these studies. Robustness was determined by changing the mobile phase flow rate from 1.0 to 0.75 and $1.25 \mathrm{~mL} / \mathrm{min}$, wavelength of detection and the concentration of methanol in mobile phase from 50 to 45 and $55 \%$.

Forced degradation studies: In order to determine the stability-indicating property and specificity of the proposed RP-HPLC method, force degradation studies were performed at various stress conditions such as acidic stress, basic stress, oxidative stress and thermal stress conditions.

For acid and base-induced degradation, the target concentration $(8 \mu \mathrm{g} / \mathrm{mL})$ of 5 -fluorouracil was freshly prepared into mobile phase. An aliquot ( $1 \mathrm{~mL}$ ) of this solution was exposed to acid and base hydrolysis by adding $4 \mathrm{~mL}$ of $1 \mathrm{M} \mathrm{HCl}$ and $4 \mathrm{~mL}$ of $1 \mathrm{M} \mathrm{NaOH}$, respectively. These mixtures were kept in hot air oven for $48 \mathrm{~h}$ at $60^{\circ} \mathrm{C}$ and then analyzed by proposed RP-HPLC method for determination of 5-fluorouracil in the presence of its acid and base degradation products, respectively.

For oxidative degradation, the target concentration $(8$ $\mu \mathrm{g} / \mathrm{mL}$ ) of 5-fluorouracil was prepared into mobile phase. An aliquot $(1 \mathrm{~mL})$ of this solution was exposed to oxidative degradation by adding $2 \mathrm{~mL}$ of $30 \%$ hydrogen peroxide $\left(\mathrm{H}_{2} \mathrm{O}_{2}\right)$. This mixture was kept in hot air oven for $48 \mathrm{~h}$ at $60^{\circ} \mathrm{C}$ and then analyzed by proposed RP-HPLC method for determination of 5-fluorouracil in the presence of its oxidative degradation products.

For thermal degradation, an aliquot of target solution (8 $\mu \mathrm{g} / \mathrm{mL}$ ) was exposed to hot air oven for $48 \mathrm{~h}$ at $60^{\circ} \mathrm{C}$ and then analyzed by proposed RP-HPLC method for determination of 5-fluorouracil in the presence of its thermal degradation products.

Solution stability studies: To ensure the reliability of the results in relation to handling and storage of stock standards, solution stability studies were performed at target concentration $(8 \mu \mathrm{g} / \mathrm{mL})$ by repeated analysis of the samples over a period of $72 \mathrm{~h}$ at ambient temperature $\left(25 \pm 1^{\circ} \mathrm{C}\right)$ and at the refrigerated temperature $\left(4 \pm 0.5^{\circ} \mathrm{C}\right)$.

Application of proposed method for the assay of 5-fluorouracil in marketed injection, developed water-in-oil nanoemulsion and double w/o/w nanoemulsion: Water-inoil nanoemulsion and double w/o/w nanoemulsion of 5-fluo- rouracil were developed and evaluated in the laboratory. To determine the 5-fluorouracil content in marketed injection (containing $50 \mathrm{mg} / \mathrm{mL}$ ), developed w/o nanoemulsion (containing $5 \mathrm{mg} / \mathrm{mL}$ of 5 -fluorouracil) and double w/o/w nanoemulsion (containing $5 \mathrm{mg} / \mathrm{mL}$ of 5 -fluorouracil), $1 \mathrm{~mL}$ of each formulation was suitably diluted with mobile phase to obtain $100 \mathrm{~mL}$ of stock solution. This solution was sonicated for $10 \mathrm{~min}$ then analyzed for drug content after suitably dilution with mobile phase. The sample obtained was analyzed for drug content. The possibility of interference of formulation components present in the formulation was studied.

\section{RESULTS AND DISCUSSION}

During method development step, use of methanol and phosphate buffer as the mobile phase resulted in asymmetric peak with a greater tailing factor $(>2)$ and less number of theoretical plates $(<2000)$. Further, acetonitrile and buffer was tried at different proportions at flow rate of $1 \mathrm{~mL} / \mathrm{min}$. A chromatograph was obtained with a poor peak. In order to get a sharp peak with asymmetry factor less than 2 and good sensitivity, methanol and water as another mobile phase were tried. Of several compositions of methanol and water tested, the binary proportion at 50:50\% v/v was found better with a sharp peak, suitable retention time and good asymmetry. Finally, proportions of the methanol and water were adjusted to obtain a rapid and simple assay method for 5-fluorouracil with a reasonable run time $(5 \mathrm{~min})$, suitable retention time $(2.53 \pm 0.01 \mathrm{~min})$ and the acceptable tailing or asymmetry factor (Fig. 1).

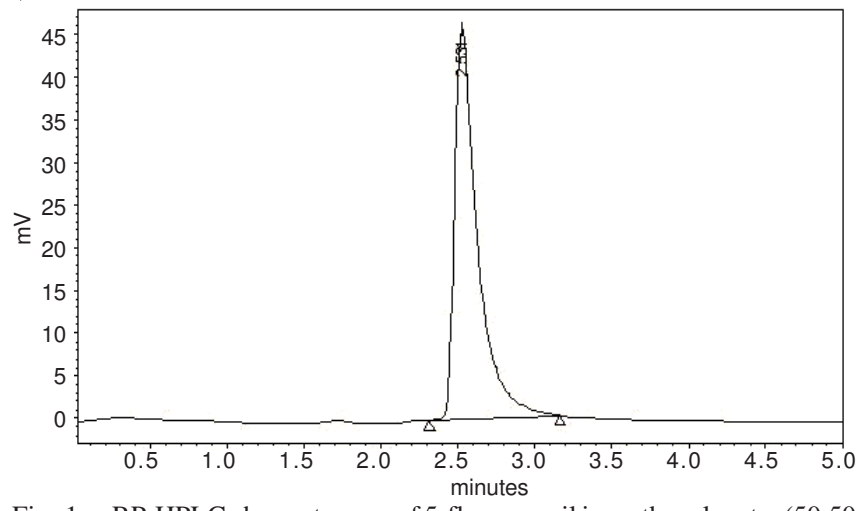

Fig. 1. RP-HPLC chromatogram of 5-fluorouracil in methanol:water (50:50 $\% \mathrm{v} / \mathrm{v})$ with retention time of $2.53 \mathrm{~min}$

Method validation: The calibration curve constructed was evaluated by linear least square analysis and correlation coefficient. The calibration curve of peak area versus concentration was found to be linear in the range of $0.1-20 \mu \mathrm{g} / \mathrm{mL}$. The equation for the calibration curve was $y=22034 \mathrm{x}+$ 3343.1. The correlation coefficient $\left(\mathrm{r}^{2}\right)$ of calibration curve was found to be 0.997 (Table-2). No significant difference was observed in the slopes of standard curves prepared (ANOVA, $p>0.05$ ). The linear regression data for calibration curve of 5-fluorouracil is shown in Table-2.

The HPLC area responses for accuracy determination were calculated as \% recovery and are shown in Table-3. Good recoveries (99.06-101.25\%) of the spiked drug were obtained at each concentration level. These results indicated the accuracy of the proposed method. 


\begin{tabular}{lc}
\hline \multicolumn{2}{c}{ TABLE-2 } \\
\multicolumn{1}{c}{ LINEAR REGRESSION DATA FOR THE } \\
CALIBRATION CURVES $(\mathrm{n}=3)$ \\
\hline \multicolumn{1}{c}{ Parameters } & Values \\
\hline Linearity range $(\mu \mathrm{g} / \mathrm{mL})$ & $0.1-20$ \\
Correlation coefficient $\left(\mathrm{r}^{2} \pm \mathrm{SD}\right)$ & $0.997 \pm 0.001$ \\
Regression equation & $\mathrm{Y}=22034 \mathrm{x}+3343.1$ \\
Slope \pm SD & $22034.00 \pm 238.07$ \\
Confidence interval of slope* & $21442.55-22625.44$ \\
Standard error of slope & 137.45 \\
Slope without intercept $\pm \mathrm{SD}$ & $22296.00 \pm 215.21$ \\
Intercept \pm SD & $3343.10 \pm 215.04$ \\
Confidence interval of intercept* & $2808.88-3877.31$ \\
Standard error of intercept & 124.15 \\
\hline$* 95 \%$ confidence interval. & \\
\hline
\end{tabular}

The results of repeatability (intraday precision) and intermediate precision were expressed in terms of \% RSD and are shown in Table-4. The developed method was found to be precise as the \% RSD values for repeatability and intermediate precision studies were found in the range of 1.34-1.99 and $0.59-1.77$, respectively. Low value of $\operatorname{RSD}(<2 \%)$ is the indication of precision of the proposed method.

The LOD and LOQ for the proposed method were determined by the standard deviation of the blank peak, as described in experimental section. The values of LOD and LOQ were found to be 0.05 and $0.15 \mu \mathrm{g} / \mathrm{mL}$, respectively, which indicated the sensitivity of the proposed method.

For robustness, the SD, \% RSD and standard error of the peak areas for all parameters (mobile phase composition, wavelength of detection and flow rate) at a concentration level of 8 $\mu \mathrm{g} / \mathrm{mL}$ are shown in Table-5. The low values of $\% \mathrm{RSD}$ and standard error obtained after introducing small deliberate changes in the mobile phase composition, wavelength of detection and flow rate indicated the robustness of the proposed method.

Forced degradation studies: The stability-indicating property and specificity of the proposed RP-HPLC method was determined by exposing a target concentration of 5-fluorouracil under various stress conditions. The drug was found to be degraded slightly under acid stress conditions. $91.25 \%$ of 5-fluorouracil was remaining in acid induced sample and only $8.75 \%$ was degraded (Fig. 2). Therefore, it was found to be stable under acidic conditions. The acid-induced degradation product (peak 2 in Fig. 2) was found to be eluted with a retention time of $2.84 \mathrm{~min}$ (Table-6).

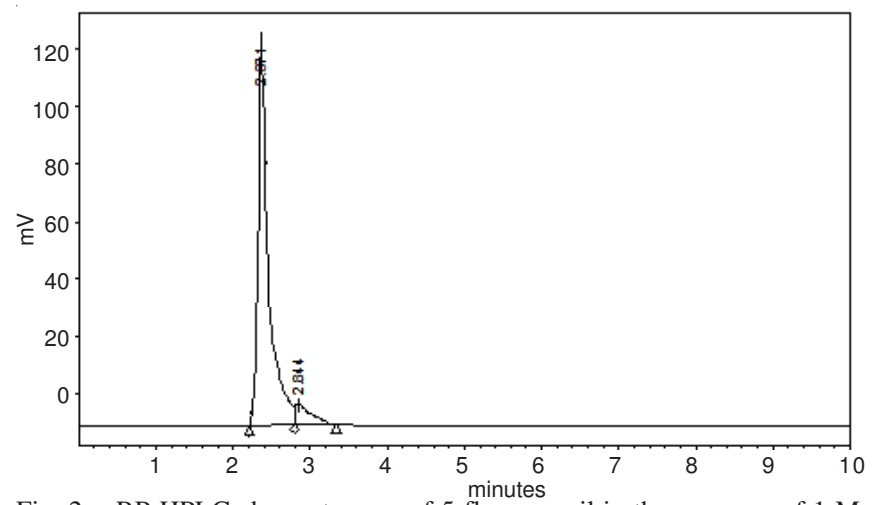

Fig. 2. RP-HPLC chromatogram of 5-fluorouracil in the presence of $1 \mathrm{M}$ $\mathrm{HCl}$

TABLE-3

ACCURACY OF THE PROPOSED METHOD (\% RECOVERY, $\mathrm{n}=3$ )

\begin{tabular}{cccccc}
\hline $\begin{array}{c}\text { Drug added to } \\
\text { analyte }(\%)\end{array}$ & $\begin{array}{c}\text { Theoretical concentration } \\
(\mu \mathrm{g} / \mathrm{mL})\end{array}$ & $\begin{array}{c}\text { Measured concentration } \\
(\mu \mathrm{g} / \mathrm{mL}) \pm \mathrm{SD}\end{array}$ & $\begin{array}{c}\text { RSD } \\
(\%)\end{array}$ & $\begin{array}{c}\text { Standard error } \\
\text { Recovery } \\
(\%)\end{array}$ \\
\hline 0 & 8 & $8.09 \pm 0.12$ & 1.48 & 0.06 & 101.25 \\
50 & 12 & $11.91 \pm 0.23$ & 1.93 & 0.13 & 99.25 \\
100 & 16 & $15.85 \pm 0.27$ & 1.70 & 0.15 & 99.06 \\
150 & 20 & $20.13 \pm 0.29$ & 1.44 & 0.16 & 100.65 \\
\hline
\end{tabular}

TABLE-4

PRECISION OF THE PROPOSED METHOD $(\mathrm{n}=3)$

\begin{tabular}{cccc|ccc}
\hline \multirow{2}{*}{$\begin{array}{c}\text { Spiked concentration } \\
(\mu \mathrm{g} / \mathrm{mL})\end{array}$} & \multicolumn{3}{c}{ Repeatability (Intra-day precision) } & \multicolumn{3}{c}{ Intermediate precision (Inter-day) } \\
\cline { 2 - 7 } & Mean area \pm SD & RSD $(\%)$ & Standard error & Mean area \pm SD & RSD $(\%)$ & Standard error \\
\hline 8 & $195791 \pm 3908$ & 1.99 & 2256 & $195012 \pm 1165$ & 0.59 & 672 \\
12 & $302097 \pm 5305$ & 1.75 & 3062 & $314623 \pm 4059$ & 1.29 & 2343 \\
16 & $421944 \pm 5693$ & 1.34 & 3286 & $425563 \pm 4098$ & 0.96 & 2366 \\
20 & $490195 \pm 8539$ & 1.74 & 4930 & $496430 \pm 8795$ & 1.77 & 5077 \\
\hline
\end{tabular}

TABLE-5

\begin{tabular}{|c|c|c|c|c|c|c|}
\hline & & ROBUSTN & $\begin{array}{r}\text { TABLE- } \\
\text { OF THE PROP }\end{array}$ & D METHOD $(n=3)$ & & \\
\hline Parameters & Mean area \pm SD & RSD (\%) & Standard error & Retention time \pm SD & $\operatorname{RSD}(\%)$ & Standard error \\
\hline \multicolumn{7}{|c|}{ Mobile phase composition } \\
\hline$(55: 45 \% \mathrm{v} / \mathrm{v})$ & $170654 \pm 1456$ & 0.85 & 840.64 & $2.57 \pm 0.01$ & 0.38 & 0.21 \\
\hline$(45: 55 \% \mathrm{v} / \mathrm{v})$ & $174876 \pm 1765$ & 1.00 & 1019.05 & $2.59 \pm 0.01$ & 0.38 & 0.21 \\
\hline \multicolumn{7}{|c|}{ Mobile phase flow rate } \\
\hline (1.25 mL/min) & $168764 \pm 1397$ & 0.82 & 806.58 & $2.24 \pm 0.02$ & 0.89 & 0.51 \\
\hline$(0.75 \mathrm{~mL} / \mathrm{min})$ & $172435 \pm 1569$ & 0.90 & 905.88 & $2.68 \pm 0.03$ & 1.11 & 0.64 \\
\hline \multicolumn{7}{|c|}{ Detection wavelength $(\mathrm{nm})$} \\
\hline 248 & $170858 \pm 1169$ & 0.68 & 674.94 & $2.58 \pm 0.01$ & 0.38 & 0.21 \\
\hline 260 & $268894 \pm 1522$ & 0.56 & 878.75 & $2.58 \pm 0.02$ & 0.77 & 0.44 \\
\hline
\end{tabular}


TABLE-6

RESULTS OF FORCED DEGRADATION STUDIES AT VARIOUS STRESS CONDITIONS ( $\mathrm{n}=3$ )

\begin{tabular}{|c|c|c|c|c|c|c|}
\hline Stress condition & Mean area \pm SD & $\begin{array}{l}\text { RSD } \\
(\%)\end{array}$ & Standard error & $\begin{array}{c}\text { Number of degradation } \\
\text { products }\left(\mathrm{R}_{\mathrm{t}}\right)\end{array}$ & $\begin{array}{l}\text { 5-FU remaining } \\
(\mu \mathrm{g} / \mathrm{ml})\end{array}$ & $\begin{array}{c}\text { Amount } \\
\text { recovered }(\%)\end{array}$ \\
\hline $1 \mathrm{M} \mathrm{HCl}$ & $164226 \pm 1362$ & 0.82 & 786.37 & $1(2.84)$ & 7.30 & 91.25 \\
\hline $1 \mathrm{M} \mathrm{NaOH}$ & $96512 \pm 1605$ & 1.66 & 926.67 & $2(4.78,5.63)$ & 4.20 & 52.50 \\
\hline $30 \% \mathrm{H}_{2} \mathrm{O}_{2}$ & $165961 \pm 1299$ & 0.78 & 750.00 & $1(5.57)$ & 7.38 & 92.25 \\
\hline Thermal & $175840 \pm 1598$ & 0.90 & 922.63 & - & 7.82 & 97.75 \\
\hline
\end{tabular}

However, it was sufficiently degraded in the presence of $1 \mathrm{M} \mathrm{NaOH}$ solution (alkaline condition). Only $52.5 \%$ of 5-fluorouracil was remaining in alkaline sample and $47.5 \%$ was degraded in $48 \mathrm{~h}$ (Fig. 3). Therefore, it was found to be unstable at alkaline conditions. The base-induced degradation products (peak 2 and 3 in Fig. 3) were found to be eluted with a retention time of 4.78 and $5.63 \mathrm{~min}$, respectively.

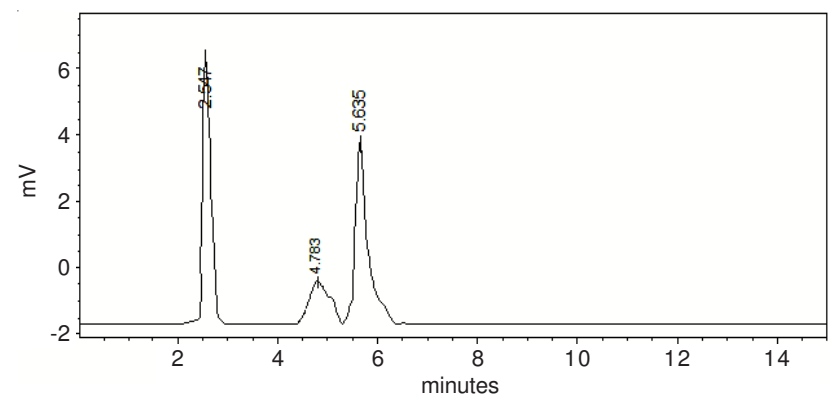

Fig. 3. RP-HPLC chromatogram of 5-fluorouracil in the presence of $1 \mathrm{M}$ $\mathrm{NaOH}$

The drug was also found to be sufficiently stable under oxidative stress conditions $\left(30 \% \mathrm{H}_{2} \mathrm{O}_{2}\right) .92 .25 \%$ of 5-fluorouracil was remaining in $\mathrm{H}_{2} \mathrm{O}_{2}$ induced sample and only 7.75 $\%$ was degraded (Fig. 4). Therefore, it was found to be stable under oxidative conditions. The $\mathrm{H}_{2} \mathrm{O}_{2}$-induced degradation product (peak 2 in Fig. 4) was found to be eluted with a retention time of $5.57 \mathrm{~min}$.

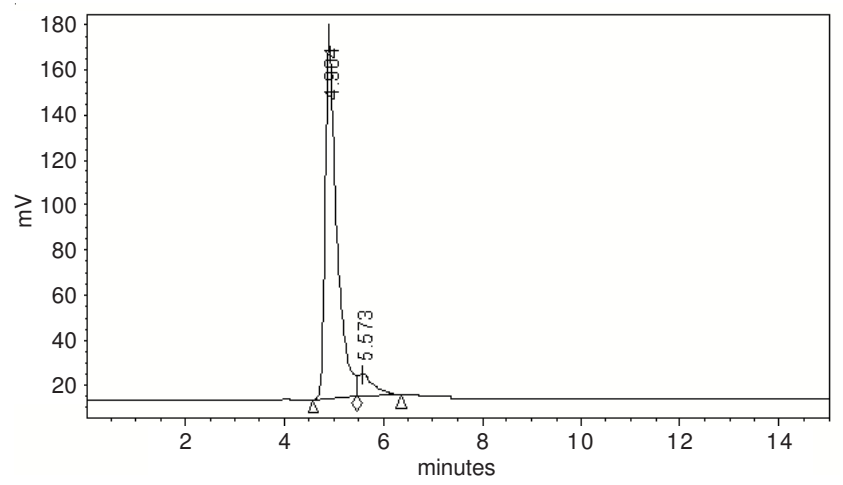

Fig. 4. RP-HPLC chromatogram of 5-fluorouracil in the presence of $30 \%$ $\mathrm{H}_{2} \mathrm{O}_{2}$

However, it was found to be highly stable under thermal stress condition. Only $2.25 \%$ of 5-fluorouracil was found to be degraded under thermal conditions and $97.75 \%$ was remaining in the solution in $48 \mathrm{~h}$ (Fig. 5). Therefore, it was found to be sufficiently stable at thermal conditions. Overall these results showed that proposed RP-HPLC method was specific and stability-indicating.

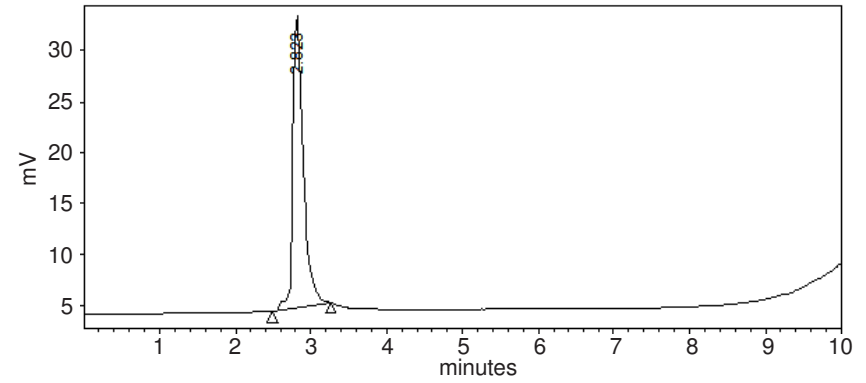

Fig. 5. RP-HPLC chromatogram of 5-fluorouracil under thermal condition

Solution stability: The drug was found to be stable when stored for $72 \mathrm{~h}$ at ambient temperature $\left(25 \pm 1^{\circ} \mathrm{C}\right)$ and under refrigeration $\left(4 \pm 0.5^{\circ} \mathrm{C}\right)$ in optimized mobile phase. More than $99 \%$ of the 5 -fluorouracil remained unchanged, on the basis of comparison of peak areas with those obtained from a freshly prepared solution of 5-fluorouracil.

Application of proposed method for the assay of 5-fluorouracil in marketed injection, developed water-in-oil nanoemulsion and double w/o/w nanoemulsion: The developed RP-HPLC method was found to be rapid, sensitive and suitable for the quantitative determination of 5-fluorouracil. Therefore this method was applied for the estimation of 5-fluorouracil in marketed injection, developed w/o nanoemulsion and double w/o/w nanoemulsion. The amount of 5-fluorouracil in marketed injection, w/o nanoemulsion and w/o/w nanoemulsion was found to be $98.95,99.25$ and $100.54 \%$, respectively. High assay value and low \% RSD (0.87-1.15) of 5 -fluorouracil in all formulations suggested that the method could be suitable for routine analysis of 5-fluorouracil in nanoemulsion formulations and marketed injections and creams. The chromatogram of 5-fluorouracil extracted from all these formulations was matching with that of pure 5-fluorouracil, showing the purity of peak in tested formulations.

\section{Conclusion}

The proposed RP-HPLC method is simple, rapid, accurate, precise, robust, sensitive and stability-indicating. The method has been found to be superior than previously reported analytical methods of 5-fluorouracil in terms of sensitivity, use of an economical mobile phase, lack of extraction procedures, lowest retention time (rapid analysis), no internal standard, UV detection and use of the same mobile phase (methanol and water) for washing of the HPLC column. All these factors make this method superior over other reported analytical methods for routine analysis of 5-fluorouracil in bulk drug and pharmaceutical formulations. The method could also be applied for prediction of shelf life in pharmaceutical formulations having 5-fluorouracil as an active ingredient because it is having stability-indicating properties. 


\section{ACKNOWLEDGEMENTS}

The authors are thankful to National Plan for Science and Technology and Innovation for generous financial support (Grant No. 11 NAN 1286-02).

\section{REFERENCES}

1. P. Rossella, B. Massimo, G. Simona and A.J. Christopher, J. Pharm. Biomed. Anal., 38, 738 (2005).

2. M. Ahmad, M. Usman, A. Madni, M. Zubair, Q.U. Zaman, M.S. Qureshi, A. Munir, M. Ahmad and A. Mahmood, Afr. J. Pharm. Pharmacol., 5, 915 (2011).

3. E.A.D. Bruijn, O. Driessen, N.V.D. Bosch, E.V. Strijen, P.H. Slee, A.T.V. Oosterom and U.R. Tjaden, J. Chromatogr., 278, 283 (1983).

4. W.B. Parker and Y.C. Cheng, Pharmacol. Ther., 48, 381 (1990).

5. G. Pattyn, J.M.R. Hollander, J.A.C.O.V.D. Panne and E.A. De Bruijn, J. Liq. Chromatogr., 13, 1173 (1990).

6. M. Barberi-Heyob, J.L. Merlin and B. Weber, J. Chromatogr. B, 581, 281 (1992).

7. W.R. Wrighston, S.R. Myers and S. Galandiuk, Biochem. Biophys. Res. Commun., 22, 808 (1995).

8. Y.S.R. Krishnaiah, V. Satyanarayana, P. Bhaskar and B. Jayaram, Asian J. Chem., 15, 1178 (2003).

9. S.P. Ackland, M.B. Garg and R.H. Dunstan, Anal. Biochem., 256, 79 (1997).

10. M. Eiji, Y. Kozo, K. Ryuichi and Y. Ken-ichiro, J. Chromatogr. B, 691, 95 (1997).

11. W. Wattanatorn, H.L. McLeod, J. Cassidy and K.E. Kendle, J. Chromatogr. B, 692, 233 (1997).

12. F. Casale, R. Canaparo, E. Muntoni, L. Serpe, G.P. Zara, C. Della Pepa, E. Berno, M. Costa and M. Eandi, Biomed. Chromatogr., 16, 446 (2002).

13. A.N. Mark, H.S. Farshad, M.C. Christine, V. Shereeni, J.M. Matshela, O. Mihail, R. Diedre, B. Susan, F. Diane, J.S. David and G. Rakesh, Int. J. Mol. Med., 10, 513 (2002).

14. D.F. Chu, J.K. Gu, W.H. Liu, J.P. Fawcett and Q.G. Dong, J. Chromatogr. $B$, 795, 377 (2003)

15. F. Casale, R. Canaparo, L. Serpe, E. Muntoni, C.D. Pepa, M. Costa, L. Mairone, G.P. Zara, G. Fornari and M. Eandi, Pharmcol. Res., 50, 173 (2004).
16. I.A. Alsarra and M.N. Alarifi, J. Chromatogr. B, 804, 435 (2004).

17. J. Ciccolini, C. Mercier, M.F. Blachon, R. Favre, A.A. Durand and B. Lacarelle, J. Clin. Pharm. Therap., 29, 307 (2004).

18. O.T. Fahmy, M.A. Korany and H.M. Maher, J. Pharm. Biomed. Anal., 34, 1099 (2004).

19. A. Di-Paolo, R. Danesi, L. Ciofi, F. Vannozzi, G. Bocci, M. Lastella, F. Amatori, B.M. Martelloni, T. Ibrahim, D. Amadori, A. Falcone and M. del Tacca, Ther. Drug Monit., 27, 362 (2005).

20. L.D. Vainchtein, H. Rosing, J.H. Schellens and J.H. Beijnen, Biomed. Chromatogr., 24, 374 (2010).

21. G. Yuan, L. Rong, S. Duanyun and L. Changxiao, Tran. Tianjin. Uni., 16, 167 (2010).

22. C. Aubert, C. Luccioni, P. Coassolo, J.P. Sommadossi and J.P. Cano, Arzneimittelforschung, 31, 2048 (1981).

23. J.L. Cohen and P.B. Brenen, J. Pharm. Sci., 62, 572 (1973).

24. M.C. Cosyns-Duyck, A.A.M. Cruyl, A.P.D. Leenheer, A.D. Schryver, J.V. Huys and F.M. Belpaire, Biol. Mass Spectrom., 7, 61 (1980).

25. C. Aubert, J.P. Sommadossi, P. Coassolo, J.P. Cano and J.P. Riqualt, Biomed. Mass Spectrom., 9, 336 (1982).

26. L. Yang, J.S. Chu and J.A. Fix, Int. J. Pharm., 235, 1 (2002).

27. D. Anderson, D.J. Kerr, C. Blesing and L.W. Seymour, J. Chromatogr. B, 688, 87 (1997).

28. G. Micoli, R. Turci, M. Arpellin and C. Minoia, J. Chromatogr. B, 750, 25 (2001).

29. Y. Morimoto, M. Akimoto, K. Sugibayashi, T. Nadai and Y. Kato, Pharmazie, 36, 155 (1981).

30. H.J. Lu, Y.L. Guo, H. Zhang and Q.Y. Ou, J. Chromatogr. B, 788, 291 (2003).

31. R.A. Fleming and C.F. Stewart, J. Chromatogr. B, 528, 517 (1990).

32. F.K. Alanazi, A.E. Yassin, M. Elbadry, H.A. Mowafy and I.A. Alsarra, J. Chromatogr. Sci., 47, 558 (2009).

33. V.R. Sinha, R.V. Kumar and R. Bhinge, Indian J. Pharm. Sci., 71, 630 (2009).

34. S.K. Banerjee and A. Sumathi, Indiam J. Pharm. Sci., 56, 42 (1994).

35. ICH, Stability Testing of New Drug Substances and Products Q1A (R2), International Conference on Harmonization, IFPMA, Geneva (2003). 